\title{
Electric Power Big Data and Its Applications
}

\author{
Defu Cai ${ }^{1}$, Hongxun Tian ${ }^{2}$, Yi Wang ${ }^{1}$, Honggang Wang ${ }^{2}$, Haifeng Zheng ${ }^{3}$, Kan Cao ${ }^{1}$ and Chu Zhou ${ }^{1}$ \\ ${ }^{1}$ State Grid Hubei Electric Power Research Institute, Wuhan 430077, Hubei Province, China \\ ${ }^{2}$ State Grid Corporation of China, Beijing 100031, China \\ ${ }^{3}$ State Grid Hubei Electric Power Company, Wuhan 430077, Hubei Province, China
}

\begin{abstract}
With the comprehensive construction of smart grid, electric power data resources rise up sharply. Make full use of electric power big data can provide an effective way for the safe operation of power grid and high-quality power supply. In this paper, the electric power enterprises' big data was divided into three classes. The source of electric power big data was introduced. The " $4 \mathrm{~V}$ " and " $3 \mathrm{E}$ " features of electric power big data were presented. Then the current situation of electric power big data was reviewed from the aspects of research and applications as well as research team building, and the engineering applications are emphatically introduced. Finally, the application scenarios of electric power big data were analyzed by three typical cases.
\end{abstract}

Keywords-big data; electric power big data; application scenarios

\section{INTRODUCTION}

With the rapid development of national economy and society as well as the continuous improvement of people's living standards, the requirements on power grid security and power supply quality are getting higher and higher. In addition, several factors make the operational environment of power system more complex and bring more challenges to the power grid security and power supply quality, such as large-scale renewable energy integration, AC/DC interconnected power grid and the gradual implementation of electricity market. Electric power big data combines the production, operation and management data of electric power enterprises. Make full use of electric power big data can provide an effective way to achieve the safe operation of power grid and high-quality power supply, and can comprehensively promote power grid to a more secure, reliable, efficient, economical, clean, interactive modern energy internet transformation.

This paper introduces the classification, source and features of electric power big data. Then the research and applications of domestic and international electric power big data are analyzed. Finally, the application scenarios of electric power big data are analyzed by three typical cases, including wind farm power prediction, low voltage location and control for distribution network, risk assessment and early warning of distribution network overload.

\section{ClassificAtion AND SOURCE OF ElECtRIC POWER BIG DATA}

The data volume of electric power industry rises up sharply with the comprehensive construction of intelligent, digital, informatized power grid. Construction and operation of power grid are the core business of electric power enterprises. These enterprises' big data can be divided into three classes, including power grid operation data, customer data and enterprise management data [1]. Power grid operation data comes from all aspects of power generation, transmission, substation, distribution, utilization and scheduling, such as power flow data, grid operation key indicators, the devices detecting or monitoring data, etc. Customer data includes electricity consumption behavior, business expansion information and other related marketing data. Enterprise management data consists of human, financial and material resources management data. According to the different data sources, electric power big data can be divided into power grid data and external data two categories [2]. Electric power enterprises big data belongs to power grid data.

Electric power big data has many resources and mainly comes from the following information collection and management systems: supervisory control and data acquisition (SCADA) system, energy management system (EMS), wide area measurement system (WAMS), operation management system (OMS), automatic dispatching system, distribution management system (DMS), electricity consumption information collection system, advanced metering infrastructure (AMI), tele-meter reading (TMR), power quality monitoring system, marketing business system, 95598 customer service system, electricity trading platform, wind power and photovoltaic power prediction system, production management system (PMS), management information system, enterprise resource planning (ERP), geographic information system (GIS), weather forecast system (WFS) and so on.

The existing information collection and management systems are relatively isolated because these systems come from different departments and the data management of different departments is isolated. The electric power big data exists problems of multi-source heterogeneity, information redundancy, different time granularity, inconsistency of statistical model and uneven data quality. These problems will pose challenges to the integrated management, analysis and processing of electric power big data.

\section{FeAtUres OF ELECTRIC POWER Big DAtA}

Electric power big data is a subset of big data in electric power industry. So it has the " $4 \mathrm{~V}$ " features of big data, including volume, variety, velocity and value. And it has the power industry unique " $3 \mathrm{E}$ " features, energy exchange and empathy [3] included. "Volume" refers to the large data capacity, which is beyond the processing capacity of 
conventional database software tool. "Variety" includes the variety of data types and data sources. "Velocity" has several meanings, including high growth rate of data, fast data transfer, high data storage speed and processing speed, high real-time demands, etc. "Value" means that the data has high value but the value density is low. "Energy" refers to that the value of electric power big data is increasing in using and refining process, which can provide guidance for the energy saving and loss reduction of electric power industry. "Exchange" means that electric power data has widespread and close connection with national economy and society. The interaction between electric power data and other industry data can bring greater value of electric power big data. "Empathy" refers to that the target of electric power enterprises is to service customer. These enterprises provide customer with high quality, safe and reliable electricity service by mining user demand.

\section{Current Situation of Electric Power Big Data}

The scientific research and engineering applications of electric power big data have been studied in European and American for a long time. Many achievements have been made in the aspects of electricity consumption behavior analysis, load forecasting, demand side management, energy efficiency and energy investment decision-making by related platforms and tools development.

The following cases are the typical application scenarios of electric power big data studied in European and American [4, 5]. The University of California at Los Angeles has developed electricity use maps of Los Angeles, which can show the electricity consumption behavior of different social groups at the block level. These maps can provide effective way for load forecasting. They can help to analyze energy investment, improve energy efficiency and develop public policy more intuitively. The massive data processing platform developed by IBM can improve the efficiency of data access and business analysis, which can be used in electricity consumption behavior and power quality analysis. The platforms developed by C3 Energy Company can be used to optimize the investment, operation and demand response of power grid and customers, including C3 energy management platform, C3 energy network analysis platform and C3 energy customer analytics platform. Opower Company analyzes customers' energy efficiency and provides energy saving suggestions based on big data analysis system. The electricity consumption information collection system developed by Electricite De France (EDF) can generate electricity consumption curve and its associated data based on the applications of a large number of smart meter and big data technology. The big data smart power research and development center established by E.ON Company and Ericsson can provide consulting and systems integration services, including remote meter reading, meter management, etc.

The electric power big data research and applications started in China later than European and American, but also made some progress. State Grid Corporation of China (SGCC) has started a number of projects on electric power big data research and applications since 2012. The first white paper on the big data problem of electric power industry was published by Chinese Society for Electrical Engineering (CSEE) in
March 2013, whose title is "China electric power big data development white paper”. The 863 project on smart grid big data was issued by Ministry of Science and Technology for the first time in 2014. The SGCC big data application guidance was issued by SGCC in 2015. SGCC comprehensively promotes the research and application of big data to promote the transformation of the company's management to data driven.

Jiangsu Electric Power Company has started the construction of marketing large data intelligent analysis system in early 2013. This system has preliminary achieved the functions of electric power seeing economy, electric power seeing livelihood and electricity consumption behavior analysis. The province daily electricity consumption can be calculated for half an hour. This system can also analyze Jiangsu industrial structure, economic trend, housing vacant rate and regional consumption capacity. The consumer daily electricity consumption can be queried by consumer search engine, which can be used to analyze electricity consumption behavior. Shandong Electric Power Company has developed the online data mining and risk early warning system for integration of dispatching and supervisory control, which can achieve the effective perception of power grid operation state and dispatching control optimization. The functions of this system comprise frequency regulation difficulty assessment, voltage regulation difficulty assessment, load characteristic analysis, security risk assessment and stability online early warning [6].

The research and development of enterprise level big data platform was started by SGCC in 2015. And SGCC has carried out several typical big data application scenarios pilot construction. Fujian Electric Power Company carried out early warning of city network distribution transformer overload for summer peak load period. Anhui Electric Power Company launched a pilot project on anti-stolen electricity early warning based on electricity consumption information collection system. Hubei Electric Power Company implemented "Liang Jia Fei Sun” analysis application. Zhejiang Electric Power Company analyzed the influence of temperature changes on electricity consumption behavior. Load forecasting was carried out at Shandong Electric Power Company. Sichuang Electric Power Company implemented electric power outage optimization in distribution network. Liaoning Electric Power Company carried out the implementation effect evaluation of policy electricity price and clean energy subsidies. Electric power grid equipment condition monitoring was carried out at Jiangsu Electric Power Company. Shanghai Electric Power Company implemented lean management of distribution network emergency repair. "Advanced computing and electric power big data technology" is classified as one of "Thirteen Five” development technologies in the SGCC "Thirteen Five” science and technology strategy research report published in 2016. SGCC is developing the big data platform covering 27 provinces (municipalities) and fully completing headquarter and provinces (municipalities) two levels big data platform.

China Southern Power Grid Company also carried out related work. Guangdong Power Grid Company developed a big data support platform of all electric power grid equipment, which can achieve comprehensive integration of 
heterogeneous information. This platform is the typical largescale online monitoring system. Shenzhen power supply Bureau carried out comprehensive evaluation on power quality based on big data.

With the increasing emphasis on the electric power big data research and applications, the domestic institutions have set up several electric power big data research teams. State Grid Information \& Telecommunication Group has set up big data research team in 2012 to cope with big data challenges in smart grid construction. Beijing Jiaotong University has established the innovation introducing talents base on active distribution network data analysis and processing in 2013. The research focuses on active distribution network, big data computation and analysis. The aim is to achieve distribution network operation real-time dynamic optimization, the main equipment monitoring and intelligent protection. China Electric Power Research Institute set up the big data management office and research team in 2014, focusing on electric power big data applications demand analysis by platform construction. Smart Grid Research Institute North America Inc. build the big data lab in 2015, which is composed of Hadoop cluster environment, data extract /transform /load platform, data mining \& exploration platform, and data analysis platform, with two hundred terabyte initial processing power and extensible capacity. This lab research focuses on customer segmentation, response targeting and energy disaggregation [7].

Currently, the pilot applications of big data technologies have extensively undertaken in power grid operation areas. But it is mainly still in the stage of data processing and statistics. Data depth mining and analysis as well as application in practical power grid operation need to be further studied.

\section{Typical ApPlicAtion SCENARIOS OF ELECTRIC POWER BIG DATA}

The application scenarios of electric power big data cover all aspects of power generation, transmission, substation, distribution, utilization and scheduling. Electric power big data has promising application prospect in renewable energy output prediction, grid security risk analysis and early warning, components maintenance scheduling, optimal dispatch, grid condition monitoring and diagnosis, equipment overall lifecycle management, power quality monitoring and assessment, low voltage location and control for distribution network, risk assessment and early warning of distribution network overload, electricity anti-stealing management, load characteristic analysis, load prediction, demand side management, user energy efficiency analysis and management, and so forth. Several typical examples are used below to further elaborate the application scenarios of electric power big data.

\section{A. Wind Farm Power Prediction}

A large number of wind farms connecting to the power grid will challenge the security and stability of power grid as well as power grid dispatching. Wind farm power prediction can be an effective way to solve this problem.
Wind farms are significantly characterizing with dispersion in spatial scale and strong random fluctuation in time scale. Wind farm power prediction needs mass data which includes historical and real-time output power data of wind farm, historical and real-time wind tower data, numerical weather prediction data, wind turbine information, operation condition of wind turbine and wind farm, topography, etc. Historical output power data of wind farm shall not be less than 1 year and the time resolution of the data should not be less than 5 minutes. Historical wind tower data should at least include $10 \mathrm{~m}, 70 \mathrm{~m}$ above elevation information such as wind velocity, wind direction, air temperature and pressure, etc. The valid duration of historical wind tower data shall not be less than 1 year and the time resolution of the data should not be less than 10 minutes [8].

Based on the above mass data, the output power of wind farm can be predicted by constructing corresponding prediction models using appropriate prediction methods. According to the diversity in predictable time scale and the specific needs of practical applications, preferably adopting various methods as well as models achieve short-term and ultra-short-term wind power prediction. Figure I illustrates the wind power prediction system developed by one wind power technology company.

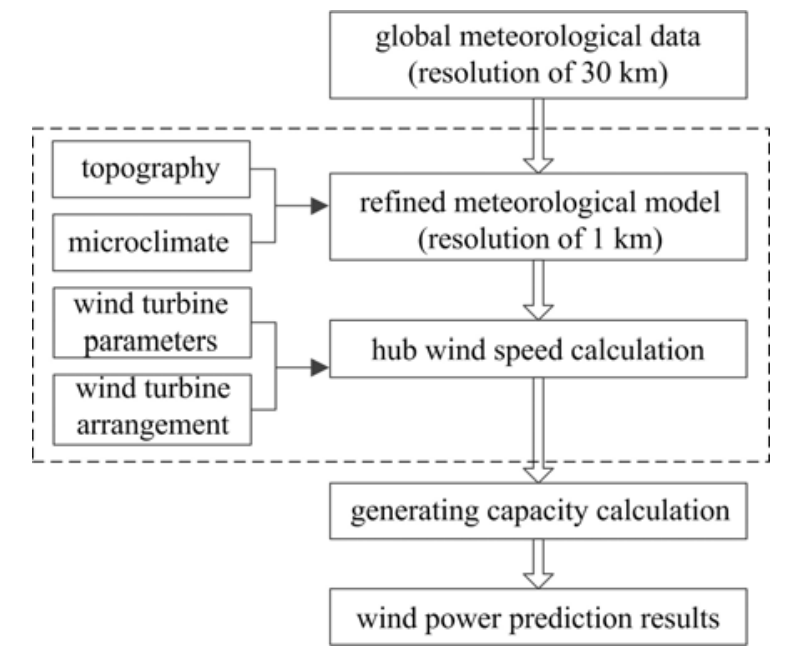

FIGURE I. THE WIND POWER PREDICTION SYSTEM DEVELOPED BY ONE WIND POWER TECHNOLOGY COMPANY

\section{B. Low Voltage Location and Control for Distribution Network}

With rapid increasing of electricity load demand and lag distribution network upgrading, nationwide distribution network emerged varying degrees of low voltage problems, which severely affected power customers' daily life and production.

The relevant data of distribution network can be collected by electricity consumption information collection system, PMS, SCADA and other systems. The data includes physical parameters (such as capacity, line diameter and power supply radius) of bus, transformer, power line, reactive compensation device and other equipment; voltage, current, power factor as well as operation and fault condition of bus, transformer and 
transmission line; load type and its active and reactive power; customer complaint of low voltage situation and so forth. Low voltage in distribution network can be located through big data analysis techniques according to above data.

The following information is associated, such as distribution network structure, distribution transformer capacity, average capacity, load rate, power supply radius, line diameter, reactive power compensation, three-phase unbalance, transformer tap position, distribution network component fault, temperature data, holidays and other information. The causes of low voltage distribution network are analyzed by influence factors data mining models and algorithms. The differentiated low voltage control measurements of distribution network are put forward from the power grid planning and operation. The different measurements' priorities are clearly set to reduce the time of distribution network voltage below the lower limit and improve voltage qualification rate. Low voltage location and control can provide decision support for planning and operation of distribution network.

\section{Risk Assessment and Early Warning of Distribution Network Overload}

The distribution network overload problem can cause great danger on power grid security and power supply quality. The information related to distribution network overload problem can be accessed by DMS, AMI, PMS, OMS, SCADA, electricity consumption information collection system, marketing business system, and other systems. These information include the historical and real-time three-phase voltage, current, active power, reactive power and power factor of distribution transformers and transmission lines in different areas (commercial, industrial and residential districts); capacity, security current and power supply radius of distribution transformers and transmission lines; distribution network structure, etc. Utilizing comprehensive analysis tools evaluate the overall characters of distribution transformers and transmission lines, load rate, capacity-load ratio, overload cumulative time, distribution network component fault rate, line load transfer ability included.

The distribution network overload early warning in different time scales can be achieved by big data technology with the following information: historical load characteristics, electricity consumption behavior, spatial load forecasting, weather factor, temperature factor, business expansion, operating characteristics of regional power grid, three-phase unbalance of distribution network and power cut scheme. Then the solutions of overload problems are provided from the perspectives of power system planning and operation. The risk assessment and early warning of distribution network overload can provide effective guidance for distribution network dispatching operation modes and also offer decision support for substation locating and its capacity determining as well as transmission line planning.

\section{CONCLUSION}

With the comprehensive construction of smart grid, electric power data resources rise up sharply. Research and application of electric power big data will provide power enterprise with advancing quality and efficiency, in addition to promote the transformation of power grid and enterprise development with a substantial driving force. This paper presented the classification, sources and features of electric power big data. The current status of electric power big data was analyzed from the aspects of scientific research, engineering application and research team building. Finally, the application scenarios of electric power big data are analyzed by three typical cases.

\section{ACKNOWLEDGMENT}

This work was supported by the Project of State Grid Corporation of China (SGTYHT/15-JS-191).

\section{REFERENCES}

[1] D. Wang, “Application of big date visualization technique in power grid enterprise,” Jiangsu Electrical Engineering, vol. 33, no. 6, pp. 82-84, 2014.

[2] D. Zhang, X. Miao, L. Liu, et al, "Research on development strategy for smart grid big data," Proceedings of the CSEE, vol. 35, no. 1, pp. 2-12, 2015.

[3] Chinese Society for Electrical Engineering Information Committee, China electric power big data development white paper[R]. 2013.

[4] M. Shi, X. Han, Z. Cheng, et al, "Research and analysis of large data application oriented to power demand side," Distribution \& Utilization, vol. 32, no. 12, pp. 20-23, 2014.

[5] D. Zhang, J. Wang, K. Liu, et al, “Application of large data technology in distribution system," Distribution \& Utilization, vol. 33, no. 8, pp. 611, 2015.

[6] M. Lei, "The online data mining and risk early warning system for integration of dispatching and supervisory control," Shandong Dianli Jishu, vol. 42, no. 5, pp. 6-8, 2015.

[7] F. Gao, G. Liu, C. Saunders, et al, "Applications of smart grid big data analytics,” Electric Power Construction, vol. 36, no. 10, pp. 11-19, 2015

[8] Q/GDW 588-2011, "Wind power prediction function specification," Beijing: China Electric Power Press, 2011. 